\title{
HbA1c -Marker for Long Term Glycemic Control
}

\author{
Ajay Puri ${ }^{1}$, Jyoti Kohli², V.J. Chrunjoo 3 \\ ${ }^{1}$ Associate Professor, Department of Biochemistry, ASCOMS Jammu, ${ }^{2}$ Associate Professor, Department of Microbiology, ASCOMS Jammu, ${ }^{3}$ Professor, Department \\ of Biochemistry, ASCOMS Jammu.
}

\section{Abstract}

Background: Protein glycation is a spontaneous reaction that is believed to play a key role in the pathogenesis of many clinical disorders. The glycation of proteins is enhanced by elevated blood glucose concentrations. The major form of protein glycation with a clinical consideration is glycated haemoglobin (HbA1c). HbA1c is majorly affected by the blood glucose levels alone. Diabetes mellitus is a metabolic disorder characterized by hyperglycemia. Studies have suggested that HbA1c levels in type-2 diabetes mellitus patients mostly remains elevated, yet some such patients, with or without tight glycemic control, have HbA1c levels nearly close to or within the normal reference range. Subjects and Methods: In this study HbA1c, fasting blood glucose levels and post prandial blood glucose levels in normal subjects as well as in patients with Type-2 diabetes mellitus excluding the complicated ones were studied. Results: The present study confirms earlier studies that all these levels are tightly correlated and the corresponding $\mathrm{p}$ values were $<0.001$ which were significant and was estimated by using student t-test. Conclusion: Thus indicating that glycated hemoglobin (HbA1c) can be used to assess the glycemic status of an individual for attaining the treatment goal of preventing long term complications of diabetes mellitus.

Keywords: Glycated Hemoglobin (HbA1C), Diabetes Mellitus (type-2 DM), Glycemic Control, Fasting Blood Glucose (FBG), Postprandial glucose (PPG)

Corresponding Author: Dr. Jyoti Kohli, Associate Professor, Department of Microbiology, ASCOMS Jammu.

Email: puria062@gmail.com

Received: November 2019

Accepted: December 2019

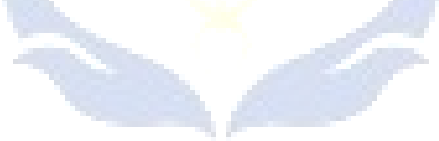

\section{Introduction}

World population of diabetics is projected to touch 366 million by $2030 .{ }^{[1]}$ Such people are at greater risk of cardiac, peripheral arterial and cerebrovascular disease. ${ }^{[2]}$ Diabetes mellitus has a major and increased deleterious impact on individual as well as national productivity.

HbA1c (glycated hemoglobin) was identified in 1980s as a potential useful marker index for use in clinical practice. ${ }^{[3,4]}$ In case of patients suffering from diabetes mellitus, it reflects on average plasma glucose over the previous 8-12 weeks. ${ }^{[5]}$ It is formed by post translational, non enzymatic, substrate concentration dependent irreversible glycation with glucose and other hexoses at the amino terminal of beta chain of $\mathrm{Hb}^{[6,7]}$

An international expert committee described $\mathrm{HbA} 1 \mathrm{c}$ value between $6.0-6.4 \%(40-42 \mathrm{mmol} / \mathrm{l})$ indicative of high risk of impaired glucose regulation (IGR). ${ }^{[8]}$ In 2011 WHO recommended use of glycated hemoglobin (HbA1c) alone as an alternative diagnostic test, suggesting an $\mathrm{HbA} 1 \mathrm{c}$ level of $>6.5 \%(>48 \mathrm{mmol} / \mathrm{l})$ as cut off for diagnosing diabetes. ${ }^{[9]}$ $\mathrm{HbA1c}$ was recommended as a widely accepted parameter for complication risks of type-2DM. ${ }^{[10]} \mathrm{HbA} 1 \mathrm{c}$ has thus been suggested as a better indicator of chronic hyperglycemia and its long term complications.

The relationship between $\mathrm{HbA} 1 \mathrm{c}$ and plasma glucose is however quiet complex. Mostly elevated HbA1c levels are found in those diabetic patients whose blood glucose levels remain persistently high. On the other hand, diabetic patients with tight glycemic control sometimes do also have HbA1c levels that are nearly close or within the reference range. For a non-diabetic individual the recommended HbA1c level is $3.5-5.5 \%$ whereas in case of diabetes mellitus, a value of $6.5 \%$ is considered as good glycemic control.

\section{Subjects and Methods}

The present retrospective study was conducted on two groups of people (135 each) of both sexes and aged 40$65 \mathrm{yr}$, attending the medicine out-patient department at ASCOMS JAMMU. Group- 1 consisted of normal subjects whereas Group-2 included patient's with type-2DM.

\section{Inclusion criteria:}

Type-2 Diabetes mellitus patients without complications and between patients of age 40-60 years.

\section{Exclusion criteria:}

Patients with history of impaired glucose tolerance, type-1 Diabetes mellitus, chronic renal diseases, retinopathies, chronic alcoholism, pregnancy. Patients with complications were excluded from the study. All the subjects of both the groups were studied for Fasting blood glucose(FBG),Post 
prandial glucose (PPG) and Glycated Hemolobin (HbA1c) levels. $2 \mathrm{ml}$ venous blood sample were drawn aseptically and put in EDTA vials. Blood sugar as well as HbA1c estimation were done using cobas c-311 auto-analyzer. The blood sugar was estimated by Hexo- kinase (Gen-3), ${ }^{[11,12]}$ and normal fasting plasma glucose value is 4.11$5.89 \mathrm{mmol} / \mathrm{L} .{ }^{[12]} \mathrm{The} \mathrm{HbA} 1 \mathrm{c}$ was estimated by turbidimetric inhibition immunoassay and its normal value was 29$42 \mathrm{mmol} / \mathrm{L}^{[13-16]}$

Statistical analysis was done by comparing both the group values and $\mathrm{p}$ - value was estimated by using student $\mathrm{t}$ - test.

\section{Results}

Table 1: Statistical comparison of parameters studied in group1 of normal healthy subjects and group 2 of type-2 diabetes mellitus.

\begin{tabular}{|l|l|l|l|}
\hline Parameters & Statistics & Group1 & Group2 \\
\hline \multirow{4}{*}{ HbA1C } & Mean & 28.50 & 73.01 \\
\cline { 2 - 4 } & SD & 4.5 & 10.01 \\
\cline { 2 - 4 } & P value & $<0.0001$ & \multicolumn{2}{|c|}{} \\
\hline \multirow{2}{*}{$\begin{array}{l}\text { Fasting plasma } \\
\text { glucose }\end{array}$} & Mean & 4.67 & 8.49 \\
\cline { 2 - 4 } & SD & 0.44 & 0.93 \\
\cline { 2 - 4 } & P value & $<0.0001$ & 13.27 \\
\hline \multirow{2}{*}{$\begin{array}{l}\text { Post prandial } \\
\text { plasma glucose }\end{array}$} & Mean & 6.33 & 1.85 \\
\cline { 2 - 4 } & SD & 0.45 & \multicolumn{2}{|l|}{} \\
\cline { 2 - 4 } & P value & $<0.0001$ & \multicolumn{2}{|c|}{} \\
\hline
\end{tabular}

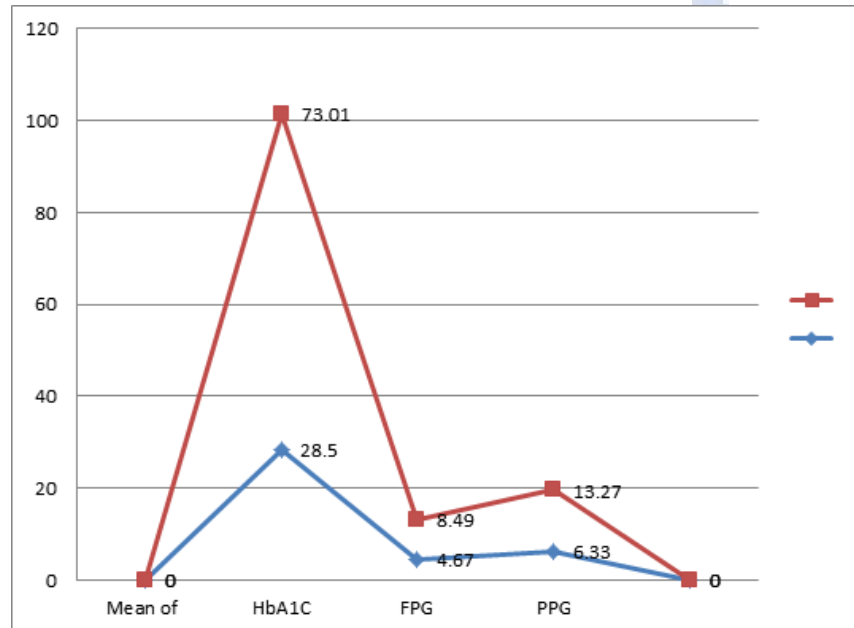

Figure 1: Comparison of mean of various parameters in group1 and group 2

As shown in the [Table 1], Fasting plasma glucose level in normal healthy subject and type-2 diabetes mellitus were statistically compared and it was observed that the mean and Standard deviation of fasting plasma glucose in group-1 and group -2 was $4.67 \pm 0.44$ and $8.49 \pm 0.93$ respectively. The $\mathrm{p}$-value for this was $<0.0001$. The postprandial glucose level in normal subjects and in type-2 diabetes mellitus patients were compared and it was shown in [Figure 1] that the mean and standard deviation in both the groups were $6.33 \pm 0.45$ and $13.27 \pm 1.85$ respectively. The corresponding $\mathrm{p}$-value for this parameter was $<0.0001$. The same way mean and standard deviation for glycated hemoglobin was compared in both the groups consisting of normal healthy subjects and type 2 diabetes mellitus patients and it was observed that the corresponding values were $28.50 \pm 4.52$ and $73.01 \pm 10.01$ respectively. The corresponding $\mathrm{p}$-value for this parameter was also $<0.0001$. As such all the observed parameter values in patients suffering from type-2 DM were significantly more higher.

\section{Discussion}

Glycated hemoglobin reflects an average plasma glucose over previous 8- 12 weeks. It is formed by post translational non enzymatic, substrate concentration dependent irreversible glycation with glucose and other hexoses at amino terminal of beta chain of hemoglobin. As such the observed parameter values of glycated hemoglobin and plasma fasting and post prandial glucose level in patients suffering from type-2 DM were significantly higher. The highly positive correlation between $\mathrm{HbAlc}$ and plasma glucose is in conformity with other studies. ${ }^{[17,18]}$ The relationship between $\mathrm{HbA1c}$ and plasma glucose levels is quiet complex . Mostly elevated glycated hemoglobin levels are found in those diabetic patients whose blood glucose levels remain persistently high. On the other hand diabetic patients with tight glycemic control sometimes do also have HbA1c levels that are nearly close or with in reference range. American diabetes association recommends $\mathrm{HbAlc}$ value below $7 \%$ for most of diabetic patients. An $\mathrm{HbA} 1 \mathrm{c}$ of $6 \%$ on average corresponds to mean plasma glucose of 135 $\mathrm{mg} / \mathrm{dl}$. For every one percent rise of glycated hemoglobin, mean plasma glucose level increases by $35 \mathrm{mg} / \mathrm{dl}$. For a nondiabetic individual the recommended $\mathrm{HbAlc}$ value is 3.5 $5.5 \%$. In case of diabetes mellitus, a value of $6.5 \%$ is considered as a good glycemic control.

Hyperglycemia causes glycosylation of all proteins and gradually causes dysfunctioning of the endothelial cells, which is a contributing factor of the atherosclerosis..$^{[2,19,20]}$ Therefore the patients are more prone to cardiovascular complications.

Tight glycemic control could improve the lipid profile of diabetic patients and can reduce the associated risk cardiovascular disease. Patients having $\mathrm{HbA} 1 \mathrm{c} \geq 7.0 \%$ were considered as diabetic dyslipidemic and those who had $\mathrm{HbA} 1 \mathrm{c}$ was $\leq 7.0 \%$ were diabetic but maintaining a good glycemic control. Most of the diabetic patients maintained a poor glycemic control that adversely affects their lipid profile and makes them prone to cardiovascular complications. Higher prevalence of dyslipidemia in diabetic patients is seen than in non-diabetic patients. The DCCT (Diabetes Control and Complications Trial) performed by National Institute of Diabetes Digestive and kidney diseases in USA have considered HbA1c as a gold standard method of glycemic control. HbA1c levels $\leq 7.0 \%$ was said appropriate in order to reduce the risks of cardiovascular complications. ${ }^{[21,22]}$ Improving glycemic control can considerably reduce the risk of cardiovascular diseases upto a great extent.

\section{Conclusion}


The present study confirms the earlier studies that HbA1c can be used to assess the glycemic status of an individual for attaining the treatment goal of preventing long term complications of diabetes mellitus. Henceforth $\mathrm{HbA1c}$ is the best indicator of chronic hyperglycemia and its long term complications. This glycated protein influences various metabolisms and play a key role in pathogenesis of various diseases.

\section{References}

1. Wild S, Roglic G, Green A, Sicree R, King H. Global Prevalence of diabetes: Estimates for the 2000 and projections for 2030. Diabetes Care. 2004;27:1047-53.

2. Euser AG, Cipolla MG. Magnesium Sulphate for the treatment of eclampsia, a brief review. Stroke 2009;40:1169-75.

3. Massi-Benedetti M. Changing targets in the treatment of type-2 diabetes. Curr Med Res Opin 2006,22 Suppl 2: S5-13.

4. Mahajan RD, Mishra B. Using glycated hemoglobin (HbA1c) for diagnosis of Diabetes Mellitus: An Indian perspective. Int J Biological Med Res 2011; 2(2): 508-512.

5. Nathan DM, Turgeon H, Regan S. Relationship between glycated hemoglobin levels and mean glucose levels over time. Diabetologia, 2007,50:2239-2244.

6. Chandalia HB, Krishnaswamy PR. Glycated Haemoglobin. Current Sci 2002; 83 (12):1522-1532.

7. ADA 2010. American Diabetes Association ,Position Statement, Diagnosis and Classification of Diabetes Mellitus. Diabetes Care, 2010; 33, Supple 1,S 62-69.

8. International Expert Committee. International Expert Committee Report on the role of HbA1c assay in the Diagnosis of Diabetes. Diabetes Care. 2009; $32: 1327-34$.

9. Use of Glycated Hemoglobin (HbA1c) in the diagnosis of Diabetes Mellitus, Abbreviated Report of a WHO Consultation 2011:1-25.

10. Canadian Diabetes Association and Clinical Practice Guidelines Expert Committee. Canadian Diabetes Association 2013. Clinical Practice Guidelines for the Prevention and Management of Diabetes in Canada 2013.
11. Kunst A, Draeger B, Ziegenhorn J. In: Bergmeyer. Methods of Enzymatic Analysis, 3rd ed. Volume VI, Metabolites 1: Carbohydrates.1984:163-172.

12. Tietz NW, ed. Clinical Guide to Laboratory Tests, 4th ed. Philadelphia. WB Saunders Company, 2006:444-451.

13. Zander R, Lang W, Wolf HU. Alkaline haematin D-575, a new tool for the determination of haemoglobin as an alternative to the cyanhaemoglobin method. I. Description of the method. Clin Chim Acta 1984;136:83-93.

14. Wolf HU, Lang W, Zander R. Alkaline haematin D-575, a new tool for the determination of haemoglobin as an alternative to the cyanhaemoglobin method.II. Standardization of the method using pure chlorohaemin. Clin Chim Acta 1984;136:95-104.

15. Little RR, Wiedmeyer HM, England JD, et al. Interlaboratory standardization of measurements of glycohemoglobins. Clin Chem 1992;38:2472-2478.

16. Jung W, Wilke B, Halabi A. Determination of reference levels in adults for haemoglobin A1c (HbA1c). Poster presentation Euromedlab, Barcelona 2003.

17. Miyazaki M, Kubo M, Kiyohara Y, Kubo KO, Nakamura H, Fujisawa $\mathrm{K}$, et al. Comparison of diagnostic methods for diabetes mellitus based on prevalence of retinopathy in a Japanese population: The Hisayoma Study. Diabetologia 2004;47(8):1411-1415.

18. Ito C., Maeda R, Ishida S, Harada H, Inoue N, Sasaki H. Importance of OGTT for diagnosing diabetes mellitus based on prevalence and incidence of retinopathy. Diabetes Res Clin Pract 2000;49(2-3):181186.

19. Mahato RV, Gyawali P, Raut P, Regmi P, Singh K, Pandeya DR, et al. Association between glycemic control and serum lipid profile in type-2 diabetic patients, Glycated hemoglobin as a dual biomarker. Biomedical research 2011;.22(3): 375-380.

20. Ikhlas k. Hameed, Baydaa A. Abed, Nada F. Rashid. Glycated hemoglobin as a dual marker associated between HbA1c and dyslipidemia in type 2 diabetic patients. J Fac Med Baghdad 2012;54:88-92.

21. The diabetes control and complicated ions Trial-(1993). Implications for Policy and practice. N Eng J Med. Vol.329,no (14),pp.1035-1036.

22. Rolhfilg CL, Wiedenmeyer HM,Little RR, England JD, Tennill A, Goldstein DE. Defining the relationship between plasma glucose and $\mathrm{HbA1c}$ in the Diabetes control and complications Trial. Diabetes Care 2013;25:275-278.

Copyright: () the author(s), 2020. It is an open-access article distributed under the terms of the Creative Commons Attribution License (CC BY 4.0), which permits authors to retain ownership of the copyright for their content, and allow anyone to download, reuse, reprint, modify, distribute and/or copy the content as long as the original authors and source are cited.

How to cite this article: Puri A, Kohli J, Chrunjoo VJ. HbA1c -Marker for Long Term Glycemic Control. Asian J. Med. Res. 2020;9(1):BC01-BC03.

DOI: dx.doi.org/10.47009/ajmr.2020.9.1.BC1

Source of Support: Nil, Conflict of Interest: None declared. 